\title{
Vulnerability Assessment of Steel Structures with Plan Irregularities Subjected to Fire
}

\author{
Bhavana Jadhav ${ }^{1 *}$, Ravindra Ramanand ${ }^{2}$ \\ 1 Research Scholar, Department of Civil Engineering, RV College of Engineering, RV Vidyaniketan Post, Mysore \\ Road, Bengaluru, Karnataka, India \\ 2 Department of Civil Engineering, RV College of Engineering, RV Vidyaniketan Post, Mysore Road, Bengaluru, \\ Karnataka, India \\ * Corresponding author's e-mail: bhavanajadhav26@gmail.com
}

\begin{abstract}
Understanding the performance of steel frames under fire loading is crucial, as numerous recent instances have revealed vulnerability of steel frames to such hazard. The present study is carried out to evaluate the vulnerability of regular and irregular steel structures in plan to fire event. Irregular buildings are encountered in practice due to various reasons. In this regard, three dimensional four storey steel moment resisting frame structures with rectangular, C-shape, $\mathrm{H}$-shape and L-shape are considered for the analysis. All moment resisting frames are subjected to five different fire cases in each floor and the most critical member is identified. The effect on stress resultants of the surrounding structural elements is investigated at critical temperatures applied to the critical member. Linear static analysis is performed and the results in terms of DCR, axial forces, bending moments and shear forces are obtained and variation in internal forces are calculated. Significant variations in the internal forces indicate that the affected column distributes force on the neighbouring members that are greater than the forces initially carried by them, potentially resulting in member failure and gradual collapse. It is observed that irregularity considerably affects the performance of the structure. The critical components of irregular structures fail at a much lower temperature when compared to regular structures. Among the various structures analysed, maximum difference in axial force, bending moment and shear forces before and after fire exposure are observed in $\mathrm{H}$-shape structure.
\end{abstract}

Keywords: demand capacity ratio; fire cases; plan irregularity; progressive collapse; vulnerability.

\section{INTRODUCTION}

Initial local failure leading to sequence of failures resulting in partial or whole structure collapse is well-defined as progressive collapse. It can trigger due to various natural or manmade aspects such as gas explosions, vehicle impact, fire, earthquake, wind, incorrect design or construction, blasts and so on $[1,2]$. Generally structures are not designed to resist these unusual occurrence and neither the effect due to such loads are thoroughly examined and hence the structures remain vulnerable to different degrees of damage. However over the years, progressive collapse phenomenon has been the topic of much attention. Research on progressive collapse due to fire began with Broadgate Phase 8 fire event in London in 1990 [3]. Since then many researchers began to investigate and understand the behaviour of steel-framed structures under fire conditions. Authors evaluated the progressive collapse of World Trade Centre twin towers under fire event [4]. Performed analysis on collapse mechanisms of the WTC towers where fire was represented by a generalised exponential curve. Geometric variations, i.e., pull-in of external columns were shown to be the primary cause of collapse that occurred at low temperatures around $400{ }^{\circ} \mathrm{C}$ [5]. Identified two probable collapse mechanisms - weak floor failure and strong floor failure of tall steel buildings exposed to multiple floor fires and proposed a design 
methodology [6]. Looked into these collapse mechanisms in more detail by conducting parametric analyses and then established the criteria on occurrence of strong and weak floor collapse mechanisms [7]. Investigated 2-dimensional and 3-dimensional models of an eight-storey steel building exposed to various compartment fires, specifying that $2 \mathrm{D}$ model yielded conservative results and that it cannot reasonably capture the accurate load redistributions [8]. Under various fire scenarios, the authors evaluated the global response of steel structures as well as local behaviour of Reduced Beam Section connections. They concluded that fire exposure over single bay had no effect on the frames overall stability but developed local buckling in the reduced section's flange and web $[9,10]$. The potential of OpenSees software to model the progressive collapse of buildings exposed to fire was explained, also presented multiple collapse mechanisms for 2D steel frames by altering the vertical loadings, sections of beam and locations of fire [11].

Investigated the column of a 20 -storey building subjected to localized fire, with emphasis on the effects during the cooling phase and mentioned that tension develops in affected column, while overloading the adjacent columns in compression possibly leading to collapse of members [12]. Through the investigations on progressive collapse of 15 storey regular and vertically irregular steel frames exposed to edge bay and middle bay fire, authors concluded that the collapse potential is higher due to fire in the edge bay when compared to the middle bay fire [13].

As per the study conducted on existing literature, most of the previous research is mainly focused on the fire response of regular steel buildings except for a very few considerations on vertical irregularities and also the members or 2D frames or compartments under study subjected to fire were selected at random. Hence the present paper builds on previous research and focusses on the plan irregularities of structure by considering 4 different structures. The objective of this work is to investigate the behavior of regular and irregular structures in plan exposed to fire by identifying the most critical member and further to assess the differences in the internal forces of the elements.

\section{DESCRIPTION OF STRUCTURAL SYSTEMS UNDERTAKEN FOR STUDY}

The four-storey moment resisting steel frame structures with four different plans are considered for the analysis. The floor areas of all the frames are kept same so as to facilitate comparative evaluation. Uniform storey-height and bay-width for all the frames are taken as $3 \mathrm{~m}$ and $4 \mathrm{~m}$ respectively. Bases of all the columns are considered to be fixed. The grade of steel for the frame members is taken as E250 as per IS 2062:201[14]. Indian Standard Heavy Weight Beams-ISHB 450@92.5 kg/m as per (SP: 6(1), 1964) [15] profile is chosen for all column and beam sections. The geometric representation of the buildings are shown in Figure 1.

\section{NUMERICAL MODELLING AND ANALYSIS}

As per the descriptions mentioned the 3D models of the regular and irregular frame structures are modelled in SAP 2000. The self-weight of members are directly computed by SAP2000, values of floor and roof live load of $2.0 \mathrm{kN} / \mathrm{m}^{2}$ and $1.5 \mathrm{kN} / \mathrm{m}^{2}$ respectively are adopted and transferred to all the beams. Wall load of $10.2 \mathrm{kN} / \mathrm{m}$ is applied on all beams. The beams and columns are subjected to uniform temperature loads. The yield stress and Young's modulus of steel material considered at ambient temperature are $250 \mathrm{MPa}$ and $210 \mathrm{GPa}$ respectively. At elevated temperature the properties of the steel are considered as per IS 800:2007 [16]. Linear Static Analysis is performed to understand the behaviour of structures.

\section{Methodology}

A linear static analysis is a type of analysis used to investigate the performance of a structure. Internal forces and deformations are obtained based on applied loads, geometry and materials. It includes materials under linear elastic behaviour and deformation concept excluding the

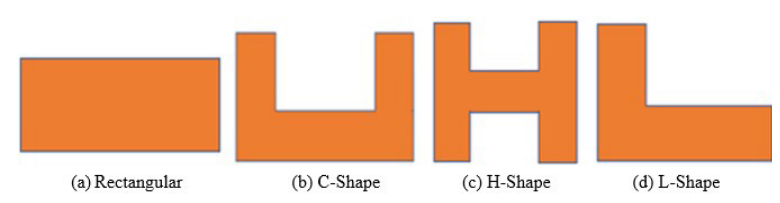

Figure 1. Geometric representations of all the buildings 
buckling phenomena. The methodology followed is as mentioned below:

- Modelling the 3-D structures with gravity loads only, perform analysis and check for the stability.

- Identify the critical members by applying temperature loads according to various fire cases.

- Note the critical temperature at which the identified vulnerable members exceed the permissible limits of DCR.

- Determine the effect of critical temperature on the stress resultants of structural elements by recording the axial forces, bending moments, shear forces of the adjoining members of structure at ambient and critical temperatures.

- Calculate the ratio of internal forces and perceive the variations before and after fire exposure.

\section{Identification of critical member based on fire scenarios}

The four different structures are initially analysed under gravity loads only. The stresses developed as well as demand capacity ratios of all the components of the structure obtained are well within safe permissible limits. After the analysis of 3D frames under gravity loadings, fire loads are considered to identify the critical components of the structure.

\section{Fire scenarios based on fire cases}

Each floor of all the four moment resisting frames considered in this study are exposed to a series of multiple-span fire cases shown in Figure 2 , to identify the most vulnerable member. Here the fire cases are expressed in terms of percentage of the floor area engulfed by fire uniformly. Five fire cases $-3.125 \%, 12.5 \%, 25 \%, 50 \%$ and $100 \%$ of the floor area are considered. In these frames, fire is considered from the first bay and according to the fire cases the corresponding floor area is subjected to fire loads of same intensity. In the above-mentioned fire cases, the temperature is applied to all the beams and columns of the bays exposed to fire.

With the application of fire loads, analysis is carried out and is observed that with the increase in temperatures the stresses of the members also increase. It is important to note that for fire cases 1,2 i.e., when the fire engulfed area is small $(3.125 \%, 12.5 \%$ of the floor area), one of the members out of those affected bays will be vulnerable to damage as expected, but for large fire scenarios $(25 \%, 50 \%$ and $100 \%)$ i.e., when the maximum or entire floor area is engulfed with fire the exterior columns, in most cases the corner columns are the one which loose their capacity and are not in a condition to sustain any further load, and such members are considered to be the most critical members.

The temperatures at which the members are failing indicate that for smaller fire scenarios (3.125\% and $12.5 \%)$ failure occurs at temperatures around $300^{\circ} \mathrm{C}$ to $400^{\circ} \mathrm{C}$. However, for large fire cases $(25 \%, 50 \%$ and $100 \%)$ failure occurs within members, at temperatures as low as $80^{\circ} \mathrm{C}$ predominantly due to large overall thermal expansion. Failure is defined as the exceeded element load carrying capacity in terms of DCR and indicates local collapse. Based on maximum bending moment and Demand Capacity Ratio (DCR) values obtained for various fire cases, the members that have exceeded the permissible limits of DCR [1] are identified as the most critical member in each floor of the structures (Figure 3), and are further considered for the study on influence of elevated temperatures on the stress resultants of elements.

Considering large fire scenarios the corner columns of Rectangular, C and L-shape structures

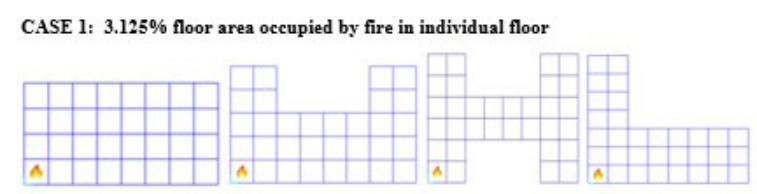

CASE 2: $12.5 \%$ floor area occupied by fire in individual floor

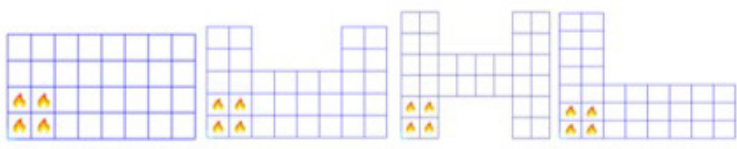

CASE 3: $25 \%$ floor area occupied by fire in individual floor

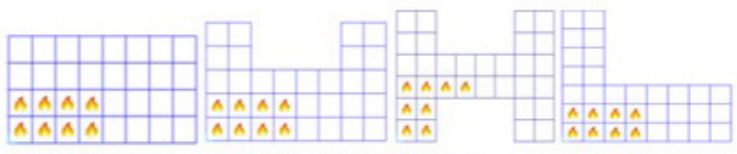

CASE 4: $\mathbf{5 0} \%$ floor area occupied by fire in individual floor

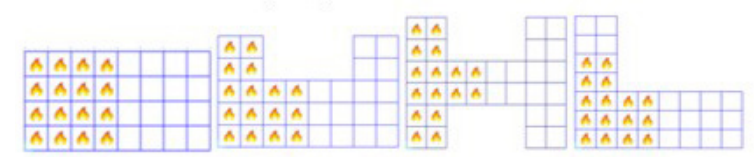

CASE 5: $100 \%$ floor area occupied by fire in individual floor

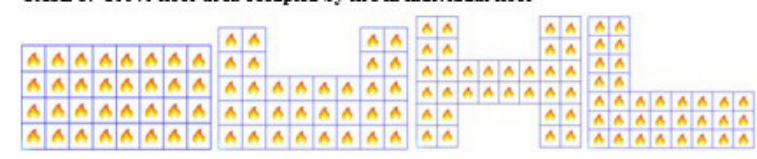

Figure 2. Fire cases applied to the moment resisting steel frames 


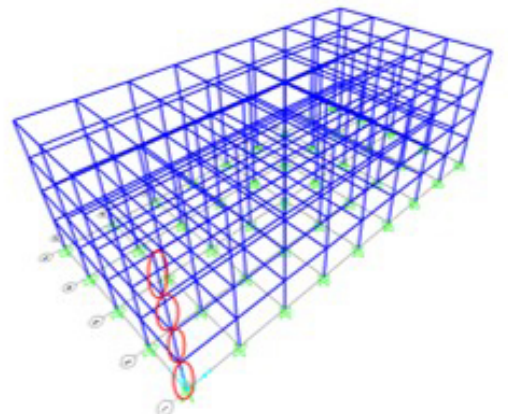

(a) Rectangular

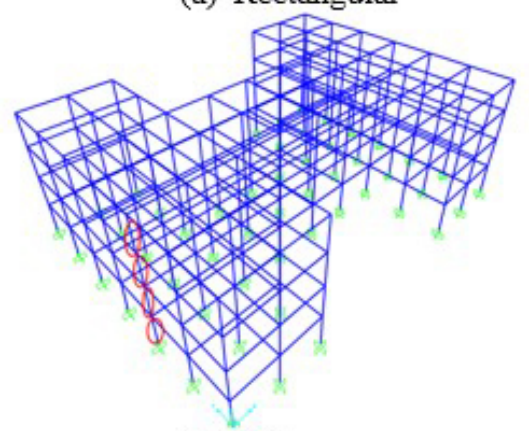

(c) H-Shape

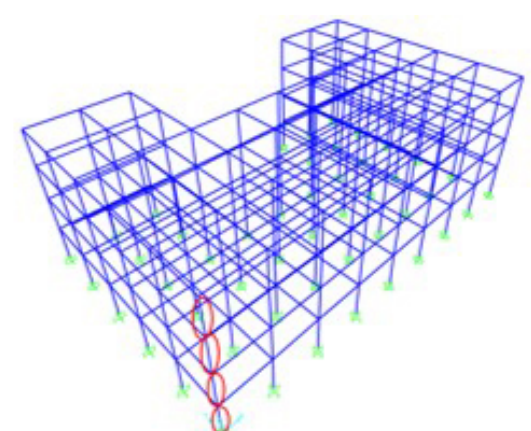

(b) C-Shape

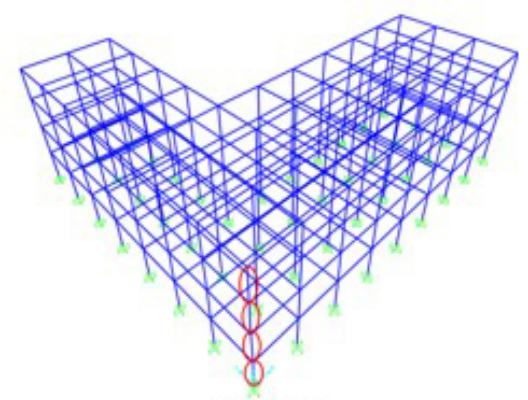

(d) L-Shape

Figure 3. Representation of critical columns at all storey levels

as shown in Figure 3(a), Figure 3(b) and Figure 3 (d) respectively, and the exterior $3^{\text {rd }}$ column in $\mathrm{y}$-direction of the H-shape structure as shown in Figure 3(c), at all storey levels are identified as the most critical components of the structure.

\section{INFLUENCE OF CRITICAL TEMPERATURE ON THE SURROUNDING MEMBERS OF STRUCTURE}

This section analyses the performance of moment resisting steel frame buildings when the critical members at all storey levels are subjected to elevated temperatures. The objective is to study the effect on the stress resultants of the neighbouring members of structure due to damage of critical members of the structure.

\section{Critical column subjected to elevated temperatures}

For this study, initially the structures are loaded with gravity loads only and then the identified critical columns at all storey levels for all models are subjected to incremental temperatures. The DCR of these critical columns at varying temperatures are obtained.
Demand Capacity Ratio (DCR) is the ratio of the force acting over a component/connection to the expected ultimate capacity of that component/ connection. As per the General Service Administration [1] guidelines the permissible limits of DCR for fully restrained moment connections is 2.0 and 1.5 for regular and irregular structures respectively. These are the acceptance limits and components exceeding these limits are considered as severely damaged.

From the obtained DCR values, the temperatures at which the column exceeds the specified acceptance limits of DCR are noted as the critical temperature at which the member will fail and probably lead to progressive collapse of the structure. From the graphs representing DCR versus temperature as shown in Figure 4, it is observed that critical temperatures of the fire exposed column are different for different structures at all storey levels and are as tabulated in Table 1 .

From Table 1, it is noted that the temperatures at which the critical column fails is more in case of rectangular shape structure when compared to all other shapes. The critical components of H-shape structure fail at a much lower temperature when compared to $\mathrm{C}$ and $\mathrm{L}$-shaped structures and hence the probability of collapse of $\mathrm{H}$-shape structure is much higher compared to the other shapes. 


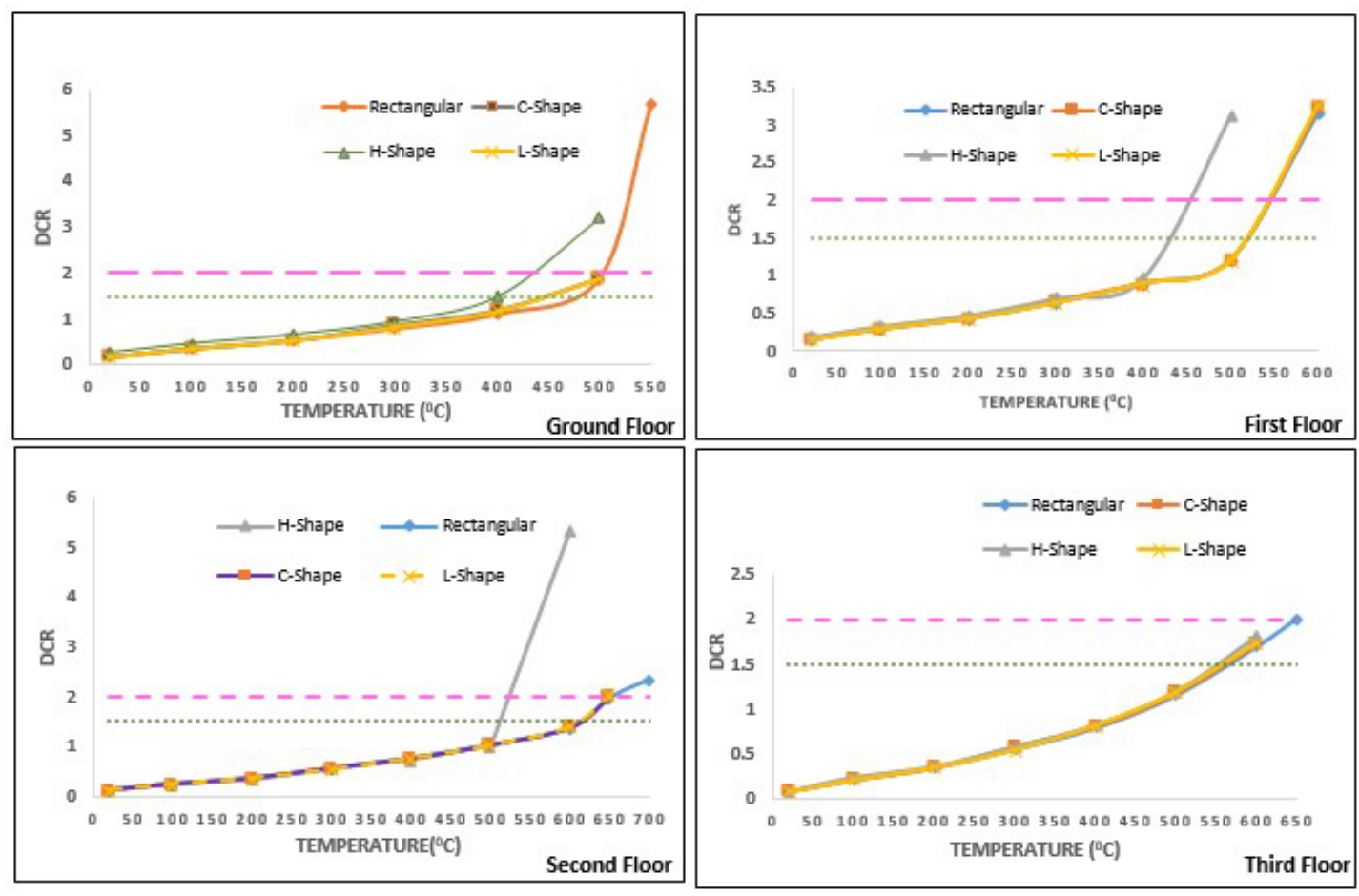

Figure 4. DCR of the fire exposed columns

Table 1. Critical temperatures at all storey levels

\begin{tabular}{|c|c|c|c|c|}
\hline \multirow{2}{*}{ Storey Level } & \multicolumn{4}{|c|}{ Critical Temperatures ('C) } \\
\cline { 2 - 5 } & Rectangular & C-Shape & H-Shape & L-Shape \\
\hline Ground Floor & 504 & 485 & 400 & 585 \\
\hline First Floor & 574 & 548 & 477 & 614 \\
\hline Second Floor & 652 & 617 & 558 & 561 \\
\hline Third Floor & 648 & 564 & 566 & \\
\hline
\end{tabular}

\section{Analysis results}

Demand capacity ratios, bending moments, axial and shear forces before and after fire exposure are obtained through linear static analysis for the members (Figures 5 and 6 ) of a specific floor that would likely be in the vicinity of the fire-exposed column. The beams and columns labels are maintained the same throughout the storeys.

To observe the load distributions and variations in internal forces of the members before and after fire exposure, the obtained results are tabulated and ratio is calculated using equation (1)

Ratio $=\frac{\text { Internal force in the member after fire }}{\text { Internal force in the member before fire }}$

\section{Demand Capacity Ratio}

The identified critical columns of the various structures at all storey levels are subjected to critical temperatures that are mentioned in the Table 1. DCR values before and after fire exposure for the columns and beams (illustrated in Figures 5 and 6), are noted. Figures 7 and 8 depicts the comparison of DCR for columns and beams respectively for various structures undertaken for study at all floor levels.

From Figures 7 and 8, it is noted that before the application of temperature the demand capacity ratios of all the beams and columns are lying within 0.5 , i.e., the values are well within the allowable limits. As the identified critical columns in each floor are subjected to critical temperatures (Table 1) the DCR values of the fire exposed column exceeds the permissible limits and undergoes failure, however the DCR of the surrounding beams and columns of the respective floors are in the range of 0.05 to 1.0 . This indicates that the damaged vertical member may have an impact on the stability of the nearby members of the structure, but will not initiate progressive collapse. In 


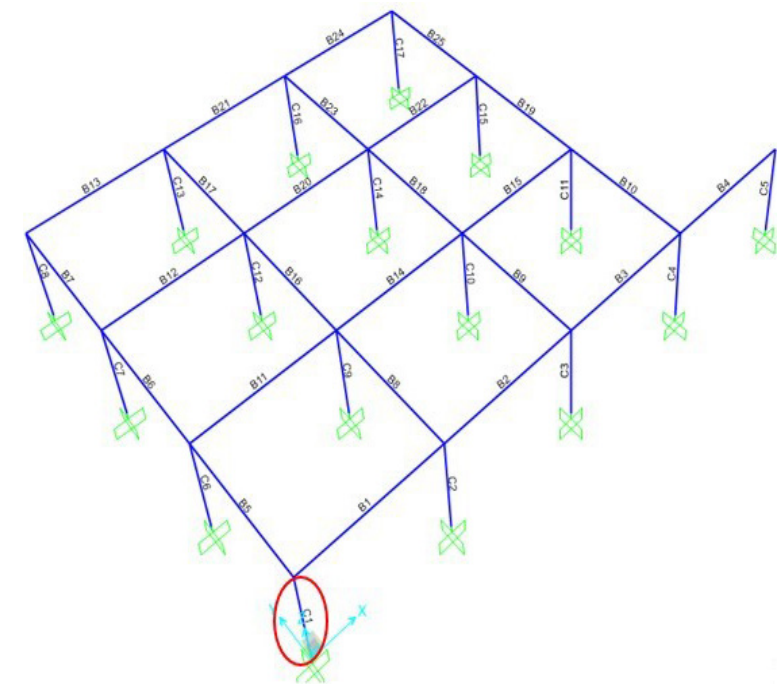

Figure 5. Beams and columns in the probable vicinity of fire exposed corner column $\mathrm{C} 1$ of Rectangular, C-shape and L- shape structures

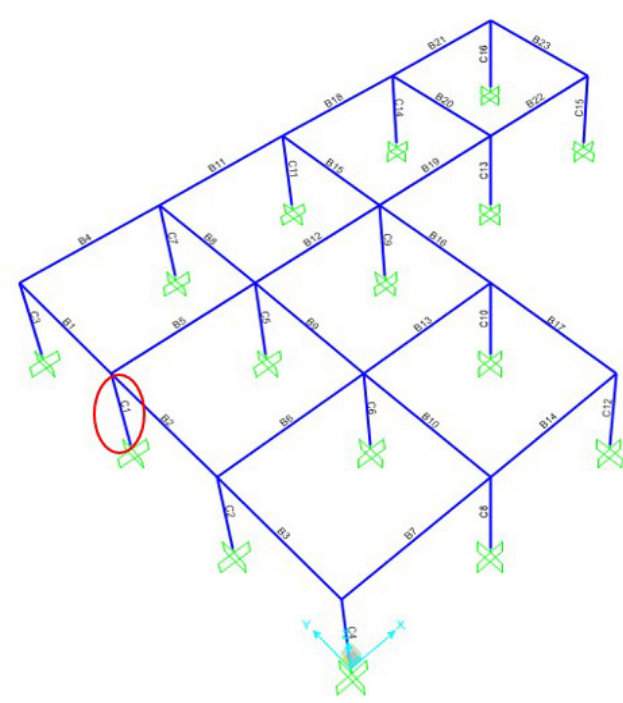

Figure 6. Beams and columns in the probable vicinity of fire exposed corner column $\mathrm{C} 1$ of $\mathrm{H}$-shape structure

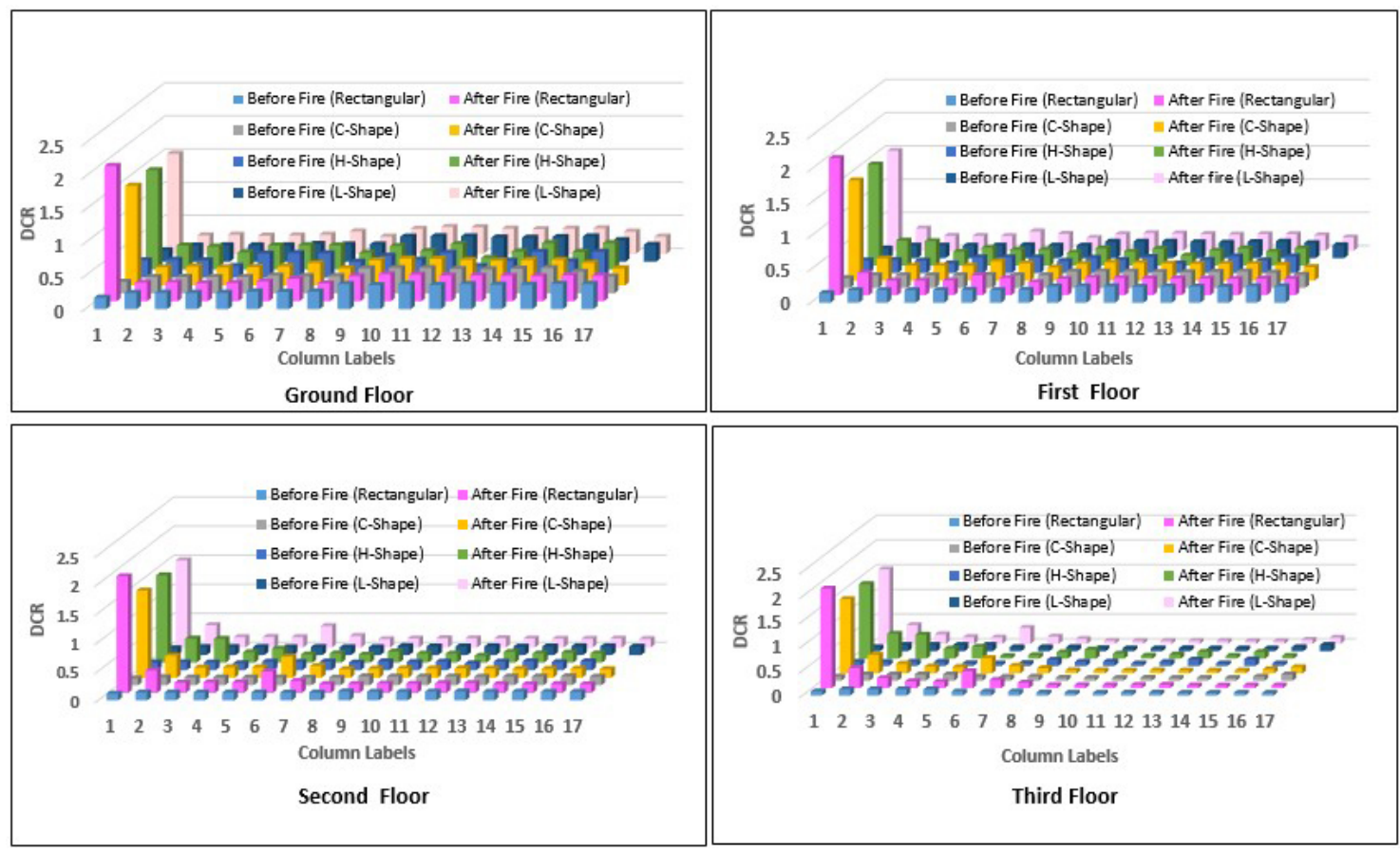

Figure 7. Demand capacity ratios of the fire exposed column and adjacent columns

comparison to other structures, the H-shape structure shows marginally higher DCR values.

\section{Axial Forces}

Critical temperatures as mentioned in the Table 1 are applied to the critical columns at all storey levels for all structures. The obtained axial forces before and after the temperature application are tabulated and the ratios as in equation 1 are calculated and plotted. A comparison of the ratio of axial forces of the column exposed to fire and the neighbouring columns (illustrated in Figures 5 and 6) for all steel frame buildings of different shapes at all floor levels is shown in Figure 9.

Initially, compressive axial forces are generated in all the columns due to gravity loads. When the column is subjected to temperatures, change in the nature of axial force from compression to tension is observed in the adjacent columns while simultaneously overloading the fire exposed column in compression. 

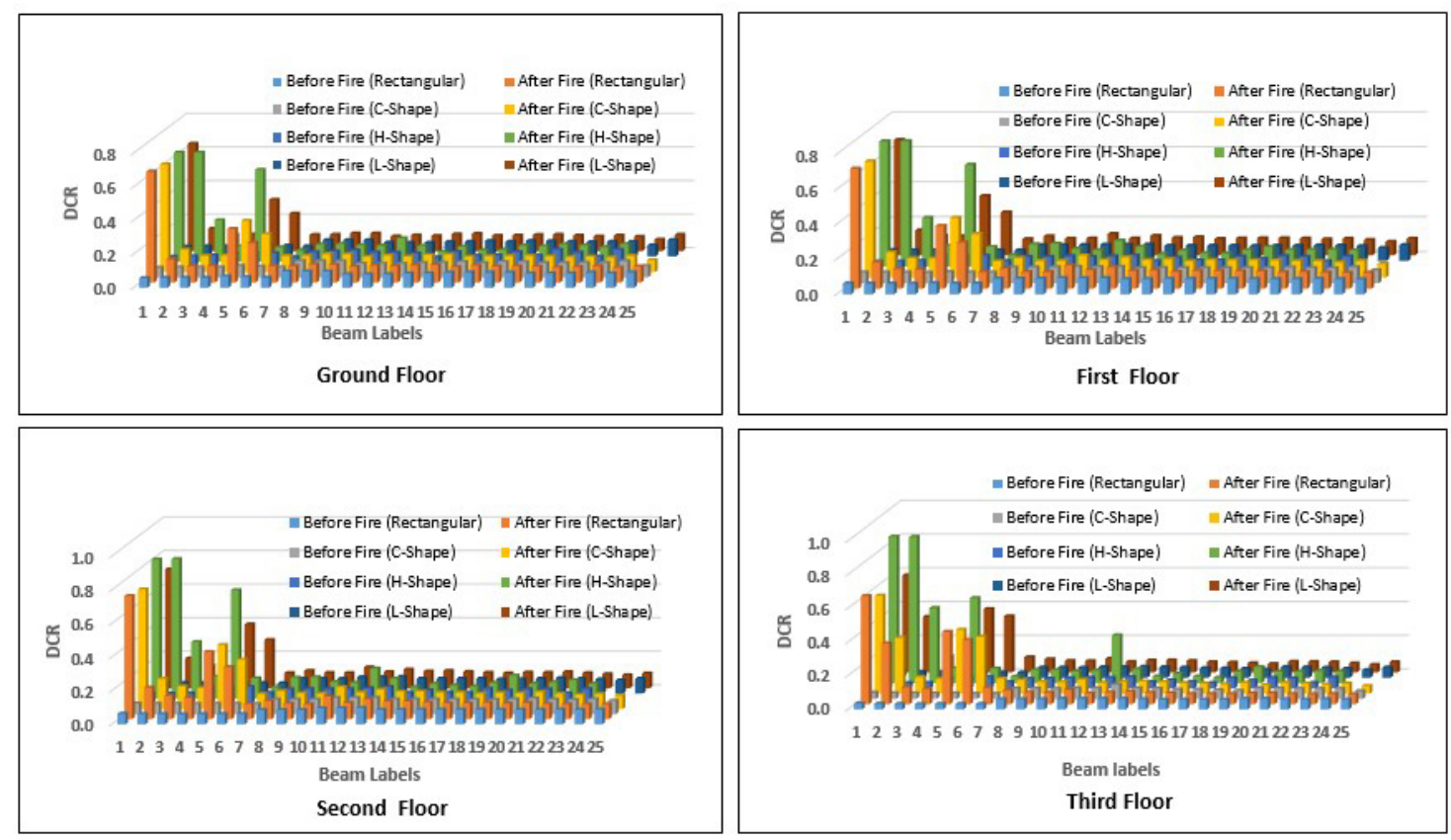

Figure 8. Demand capacity ratios of the surrounding beams

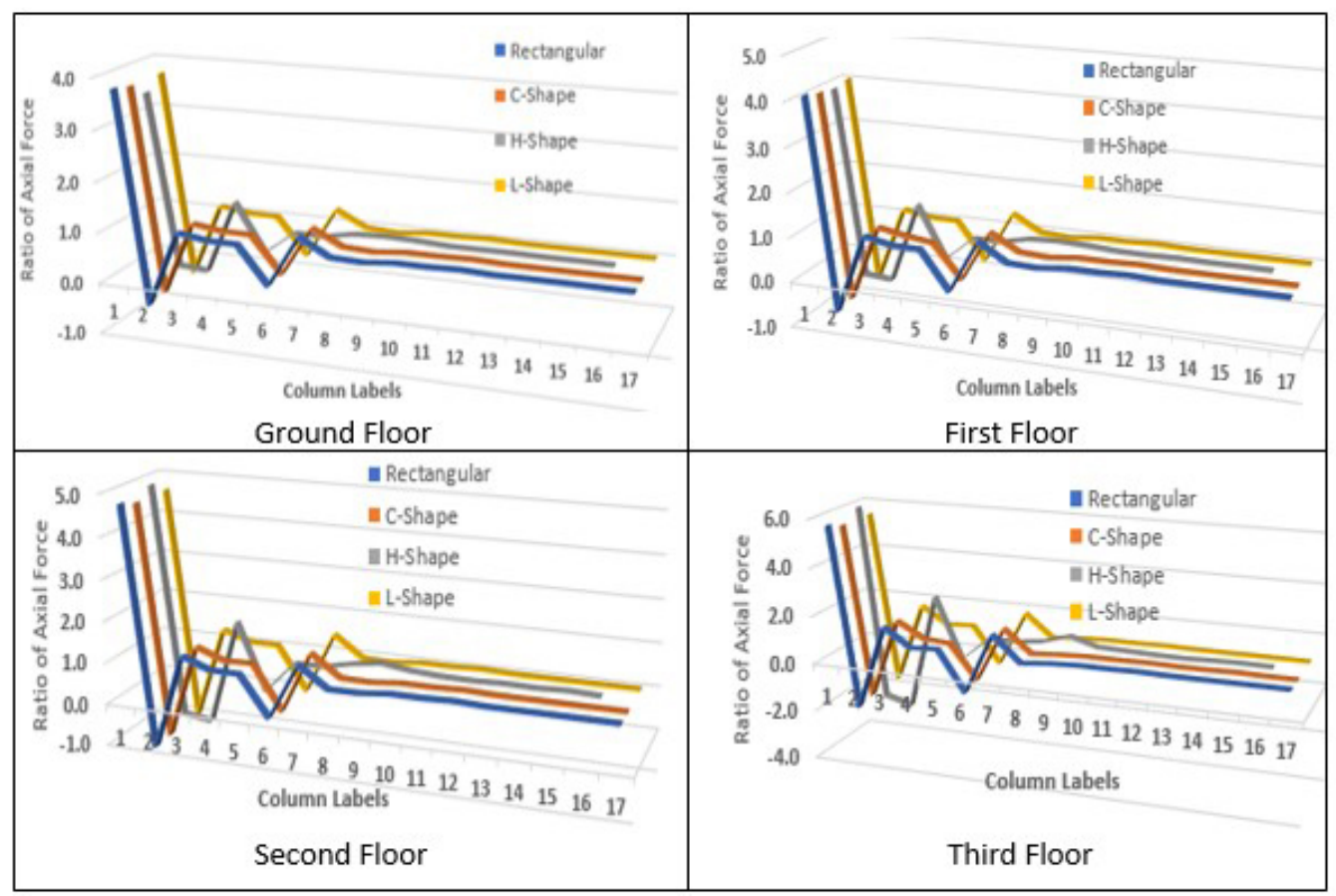

Figure 9. Ratio of axial forces before and after fire

It is seen from Figure 9, that the change in axial forces in case of rectangular, $\mathrm{C}$ and $\mathrm{L}$ - shape structures is maximum for the fire exposed column $\mathrm{C} 1$ when compared to the other columns that are relatively away from the affected column in all floors and in the immediate adjacent columns C2 (refer Figure 5) the ratio shifts from positive to negative indicating the change in the nature of axial force from compression to tension. In case of $\mathrm{H}$-shape structure the columns C1, C2 and C5 (refer Figure 6), has huge variations in axial force in comparison to the other columns. Among the different plan irregularities, H-shape structure shows maximum difference in axial forces in spite of low critical temperatures.

\section{Bending Moment (BM) in Columns}

Critical columns of all structures at all levels are subjected to temperatures mentioned in 


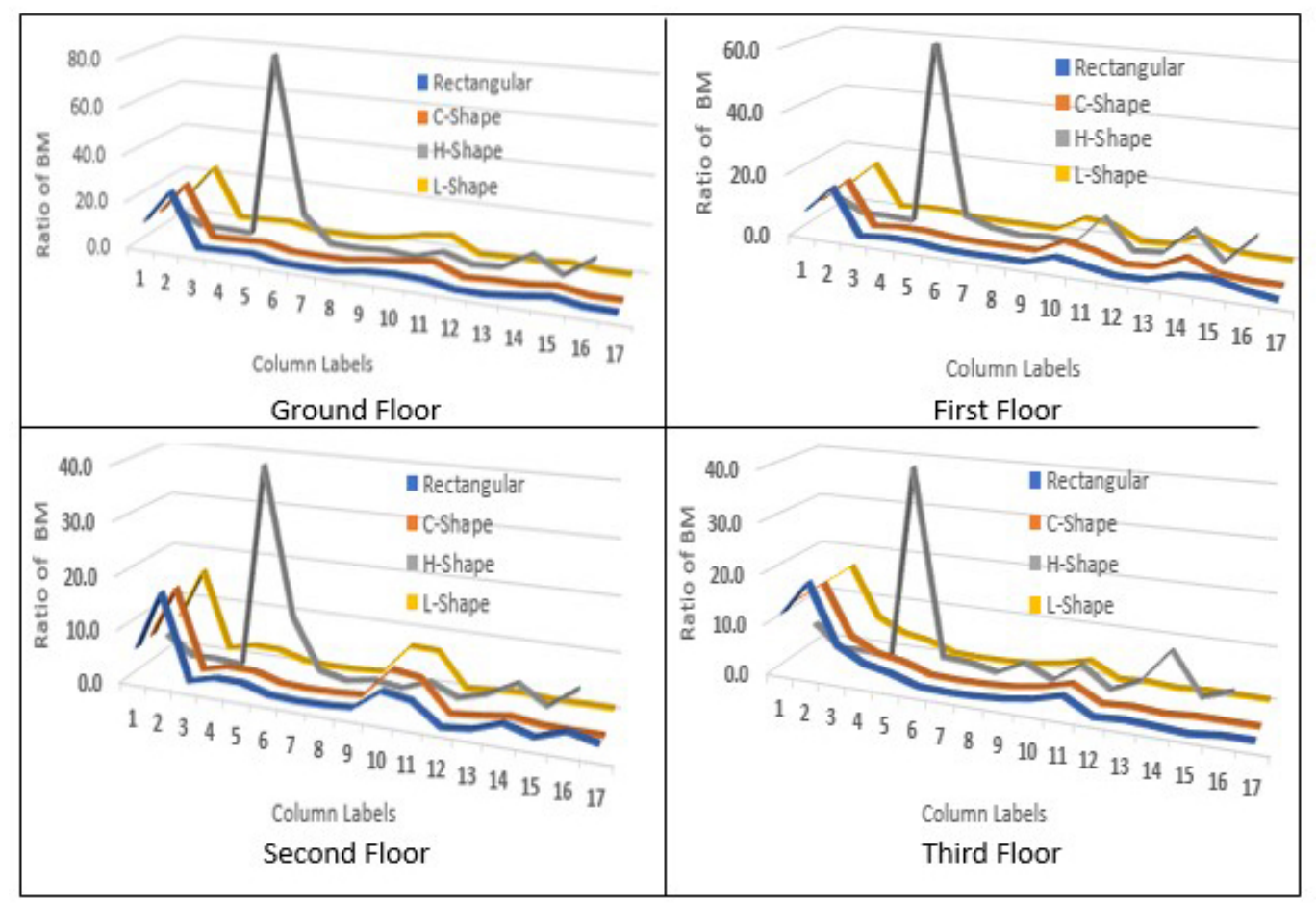

Figure 10. Ratio of bending moment of columns before and after fire

Table1. The maximum bending moments obtained before and after the critical temperature application are noted, the ratios are calculated and plotted for the affected column and the other surrounding members mentioned in Figures 5 and 6 . While plotting the graphs sign conventions of bending moments and shear forces are neglected and only the ratios have been represented.

Figure 10, represents the ratio of bending moment of columns before and after fire, of the fire exposed column and neighbouring columns of the regular and irregular structures at all storey levels.

For rectangular, C-shape and L-shape structures the maximum change in bending moment is observed in the adjacent column C2 (refer Figure 5) at all floors when compared to the other columns that are far away from the damaged column. In case of $\mathrm{H}$-shape structure the adjacent column $\mathrm{C} 5$ (refer Figure 6) is having maximum variation in $\mathrm{BM}$ in comparison to the other columns. Out of four structures, even though the temperatures applied for $\mathrm{H}$ shape building are low, highest variations in BM are observed for this structure at all floor levels.

\section{Bending Moment (BM) in beams}

Due to temperatures applied to the critical column, enormous differences are observed in the bending moments of the beams. Figure 11, indicates the ratio of bending moment plotted for the beams displayed in Figures 5 and 6 .

From Figure 11, it is noted that the beams B1and B5 that are directly connected with the fire exposed column in case of rectangular, C and L-shape structures show large variations in bending moments in comparison to the neighbouring beams that are away from the affected column. For H- shape structure also the beams B1, B2 and B5 connected directly to the affected column show large difference when compared to other beams at all levels. Large bending moments develop in beams due to expansion of the columns. Similar to the axial force and $\mathrm{BM}$ in columns, the ratios of $\mathrm{BM}$ of beams are the highest in case of $\mathrm{H}$-shape building

\section{Shear Force in beams}

For the adjoining beams linked with the fire exposed column and other nearby beams (Figures 5 and 6) the maximum shear forces obtained from the analysis before and after fire exposure are noted. Figure 12, indicates the ratio of shear force for various beams at all floor levels.

In case of rectangular, $\mathrm{C}$ and L-shape structures maximum changes are observed in the beams B1 and B5 connected with the affected column when compared to other neighbouring beams that are relatively away. For H-shape structure the beams B1, B2 directly connected to 

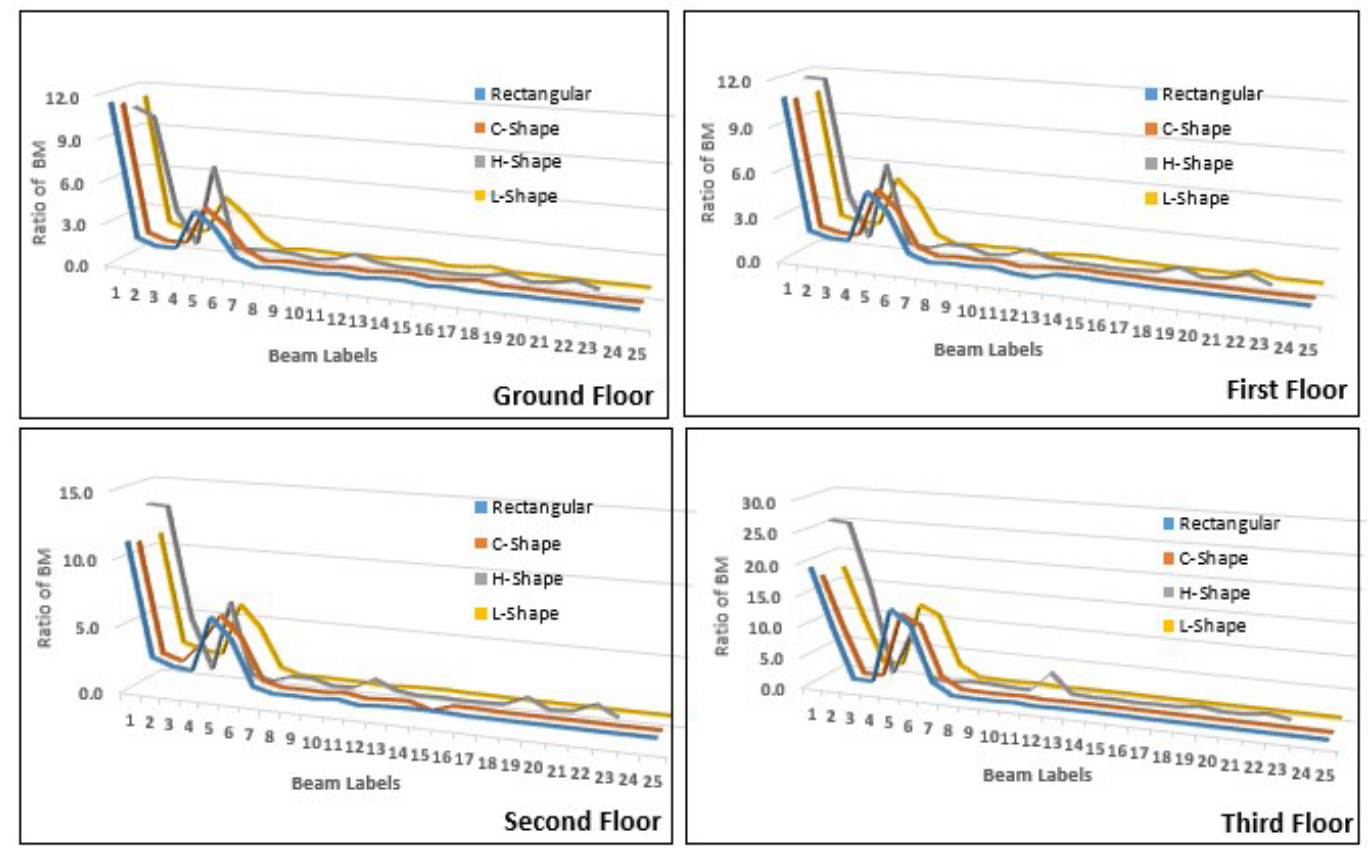

Figure 11. Ratio of bending moment of beams before and after fire
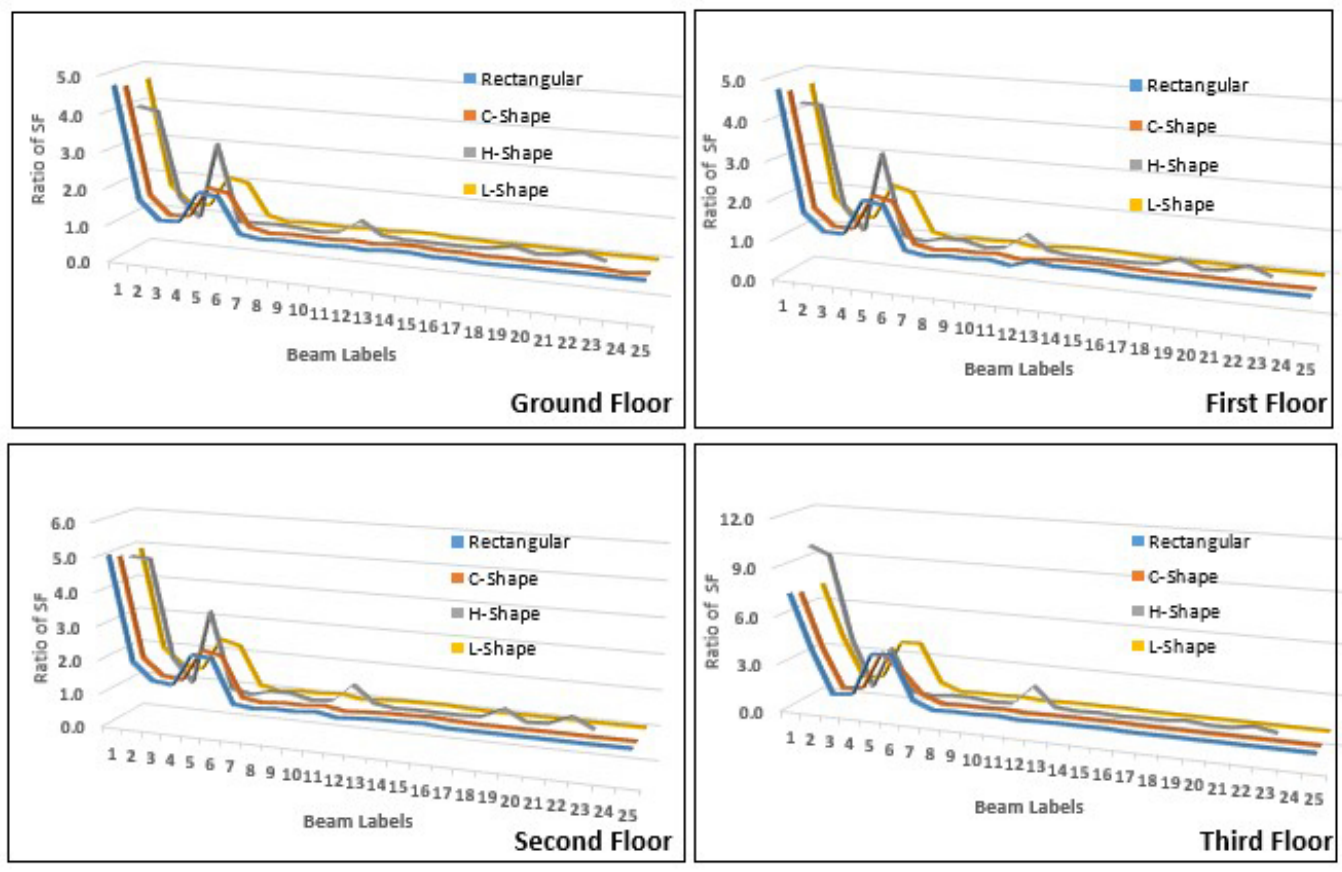

Figure 12. Ratio of shear force of beams before and after fire

the damaged column show significant variations, also beam B5 shows more differences in comparison to other beams.

\section{CONCLUSIONS}

The behaviour of regular and irregular moment resisting steel frame structures subjected to fire are studied and the following conclusions are drawn. In case of small fire scenarios $(3.125 \%$ and $12.5 \%)$, members connected with the affected areas will be susceptible to damage and member failure occurs at temperatures around $300^{\circ} \mathrm{C}$ to $400^{\circ} \mathrm{C}$. However, for large fire scenarios $(25 \%, 50 \%$ and $100 \%)$ the exterior columns, especially the corner columns are vulnerable and fail at temperatures as low as $80^{\circ} \mathrm{C}$ due to large overall thermal expansion. 
Based on the maximum bending moment and DCR values obtained for various fire cases, members exceeding the permissible limits of DCR are identified as the most critical member in each floor of the structures-Corner column (In case of Rectangular, C and L-shaped structures) exterior $3^{\text {rd }}$ column in y direction (H-shape structure). This also explains the research gap mentioned in literature.

The critical components of H-shape structure fail at a much lower temperature when compared to other structures and hence the potential of collapse of H-shape structure is much higher compared to the other shapes.

At critical temperatures the demand capacity ratio of the fire exposed column exceeded the permitted limits, but the DCR of the neighbouring members were with-in the limits at all storey levels and hence the structures will not undergo progressive collapse.

The change in axial forces is maximum in the fire exposed column and the immediate adjacent columns when compared to other members that are away from the damaged column. Among all the different frames the H-shape structure shows maximum difference in axial forces in spite of low critical temperatures.

The beams directly connected with the critical column indicate huge variations in bending moment and shear forces when compared to the other beams that are at a distance away from the affected column. Amongst all the types of structures undertaken for study, the ratio of BM in beams and columns and ratio of SF of beams are highest in case of $\mathrm{H}$-shape building.

Hence H-shaped structures in plan are more vulnerable to failure in case of fire loads.

\section{REFERENCES}

1. U.S. General Service Administration, "Progressive Collapse Analysis and Design Guidelines for New Federal Office Buildings and Major Modernization Projects", 2003.

2. Starossek U., P.E., ASCE M., Haberland M. Disproportionate collapse: terminology and procedures. Journal of Performance of Constructed Facilities. 2010; 24(6):519-528. https://doi.org/10.1061/ (ASCE)CF.1943-5509.0000138

3. British Steel, "The Behaviour of a Multi-storey Steel Framed Building Subject to Fire Attack", British Steel plc., Swinden Technology Center, Moorgate, Rotherham, UK, 1998.
4. Usmani A.S., Chung Y.C., Torero J.L. How did the WTC towers collapse: a new theory. Fire Safety Journal. 2003; 38(6):501-533. https://doi. org/10.1016/S0379-7112(03)00069-9

5. Flint G., Usmani A., Lamont S., Lane B., Torero J. Structural response of tall buildings to multiple floor fires. Journal of Structural Engineering. 2007; 133(12):1719-1732. https://doi.org/10.1061/ (ASCE)0733-9445(2007)133:12(1719)

6. Lange D., Roben C., Usmani A. Tall building collapse mechanisms initiated by fire: mechanisms and design methodology. Engineering Structures. 2012; 36: 90-103. https://doi.org/10.1016/j.engstruct.2011.10.003

7. Kotsovinos P., Usmani A. The World Trade Center 9/11 Disaster and progressive collapse of tall buildings. Fire Technology. 2013; 49(3): 741-765. DOI: $10.1007 / \mathrm{s} 10694-012-0283-8$

8. Jiang J., Guo Qiang Li. Disproportionate collapse of 3D steel-framed structures exposed to various compartment fires. Journal of Constructional Steel Research. 2017; 138: 594 - 607. https://doi. org/10.1016/j.jcsr.2017.08.007

9. Memari M., Mahmoud H. Performance of steel moment resisting frames with RBS connections under fire loading. Engineering Structures. 2014; 75: 126-138. https://doi.org/10.1016/j.engstruct.2014.05.040

10. Memari M., Mahmoud H. Multi-resolution analysis of the SAC steel frames with RBS connections under fire. Fire Safety Journal. 2018; 98: 90-108. DOI: $10.1016 /$ j.firesaf.2018.04.008

11. Jiang J., Guo-Qiang Li, and Usmani A. Progressive Collapse Mechanisms of Steel FramesExposed to Fire. Advances in Structural Engineering. 2014, 17(3): 381-398 https://doi.org/10.1260/13694332.17.3.381

12. Gernay T. \& Gamba A. Progressive collapse triggered by fire induced column loss: Detrimental effect of thermal forces. Engineering Structures. 2018; 172: 483-496. DOI: 10.1016/j. engstruct.2018.06.060

13. Heshmati M., Aghakouchak A.A. Collapse analysis of regular and irregular tall steel moment frames under fire loading. The Structural Design of Tall and Special Buildings. 2019, 29(3): 1-19. https:// doi.org/10.1002/tal.1696

14. IS 2062: 2011 - "Indian Standard Hot Rolled Medium and High Tensile Structural Steel" — Specification

15. SP: 6(1) - 1964 - "Handbook For Structural Engineers: Structural Steel Sections"

16. IS 800:2007- "Indian Standard General Construction in Steel - Code of Practice" 